\title{
Model Evaluasi Penerimaan Pengguna Sistem Informasi Rekam Medis di Sektor Kesehatan
}

\author{
Ni Kadek Armini*, Aris Puji Widodo**, Suhartono** \\ * Sekolah Tinggi Ilmu Kesehatan Indonesia Jaya Palu, Sulawesi Tengah, \\ * Fakultas Kesehatan Masyarakat, Universitas Diponegoro, Semarang \\ Email: ni kadekarmini@yahoo.co.id
}

\section{ABSTRACT}

In the development of advanced technology, information users are required to follow the progress that has grown rapidly. One of the programs implemented by the Ministry of Health of the Republic of Indonesia has issued a policy that guides the implementation of health development implemented by the government and private sector in order to improve the quality of information in this case the quality of medical record information. And one of the efforts to improve the quality of medical record information in the hospital in the form of the application of Medical Record Information System (SIRM). Application of SIRM is currently experiencing obstacles and barriers in the level of user acceptance. There are still many things that are operational and managerial, making the implementation of SIRM is not going well. . This study evaluates the results of SIRM implementation to process the data of inpatients at Undata Hospital of Central Sulawesi Province from the user acceptance level, using the combined model of Unified Theory of Acceptance and Usage of Technology (UTAUT) and Human, Organization, Technology Fit (HOT Fit ).
Keywords: SIRM; Acceptance Model of integration of UTAUT and HOT Fit

\section{PENDAHULUAN}

Perkembangan bidang teknologi dan sistem informasi yang pesat memberi pengaruh di segala bidang kehidupan manusia termasuk bidang kesehatan. Berbagai aplikasi dibuat dan dikembangkan untuk menunjang dan membantu operasional pelayanan kesehatan, aplikasi tersebut diharapkan dapat digunakan dalam proses pengambilan keputusan yang bermanfaat di bidang kesehatan.

Berkembangnya teknologi informasi dan komunikasi merupakan kondisi positif sangat mendukung berkembangnya sistem informasi kesehatan. Salah satu upaya meningkatkan kualitas informasi kesehatan dalam hal ini kualitas informasi rekam medis dimana catatan medik merupakan alat yang digunakan untuk mengolah data statistik rumah sakit. Hasil kerja statistik yang lengkap dan teraturnya laporan data rumah sakit akan menunjang hasil yang sempurna guna pengambilan keputusan secara bijaksana untuk pengembangan rumah sakit kedepannya. ${ }^{1}$ Untuk itu rumah 
sakit di Indonesia sudah mulai menerapkan Sistem Informasi Rekam Medis (SIRM). Penerapan SIRM di lingkungan rumah sakit merupakan proses perubahan yang menuntut kesiapan pengguna agar penerapan tersebut berhasil. Penerapan SIRM tersebut akan membawa perubahan dalam peningkatan kualitas informasi sehingga keputusan yang diambil manajemen tepat sasaran.

Salah satu rumah sakit yang mulai menerapkan SIRM adalah RSUD Undata Provinsi Sulawesi Tengah. Dengan diterapkannya SIRM diharapkan mampu memenuhi harapan pengguna akan tersedianya informasi yang berkualitas yaitu informasi yang cepat, akurat dan relevan. Namun dalam pelaksanaannya masih banyak kendala-kendala dan hambatan ditingkat penerimaan pengguna, masih banyaknya hal yang bersifat operasional dan manajerial, membuat penerapan SIRM tidak berjalan baik.

Permasalahan yang ada saat ini di RSUD Undata di bagian rekam medis adalah input data dilakukan berulang-ulang, proses pelaporan eksternal \& internal untuk rumah sakit maupun dinas tidak menggunakan output dari SIRM, tetapi menggunakan laporan yang dibuat dengan spreadsheet secara manual, sehingga beban kerja pengguna sistem bertambah serta penyajian informasi tidak tepat waktu lebih dari 6 jam bahkan sampai 5 bulan berjalan belum ada laporan. Selain itu masalah kualitas petugas SIRM juga masih rendah karena karena pelatihan belum dilaksanakan terkait penggunaan sistem informasi jadi dilakukan sebatas sosialisasi.

Berdasarkan hal tersebut, maka perlu untuk evaluasi penerimaan penggunaan SIRM dengan metode HOT Fit dan UTAUT. Pada model HOT Fit menempatkan tiga faktor penting, yaitu faktor organisasi, teknologi dan manusia. Teori HOT Fit belum menjelaskan secara lebih jauh faktorfaktor yang mempengaruhi penerimaan penggunaan SI. ${ }^{2}$ Model penerimaan SI pada HOT Fit terdiri dari tiga faktor penting yang ada dalam UTAUT yaitu harapan kinerja, harapan usaha dan pengaruh sosial. $^{3}$ Tujuan dari penelitian ini adalah untuk mengetahui gambaran sejauh mana persepsi pengguna terhadap penerimaan penggunaan SIRM di RSUD Undata Provinsi Sulawesi Tengah.

\section{METODE PENELITIAN}

Rancangan penelitian ini menggunakan rancangan deskriptif dan kualitatif yang bertujuan untuk menggali secara mendalam mengenai penerapan Sistem Informasi Rekam Medis (SIRM) dalam hal pengolahan data rekam medis pasien rawat inap dan memperoleh gambaran komprehensif mengenai persepsi penerimaan pengguna pada penerapan SIRM dengan model evaluasi integrasi antara HOT Fit dan UTAUT yang dapat dilihat pada Gambar 3.1. Penelitian dilaksanakan pada bulan April sampai dengan Mei tahun 2017 yang berlokasi di RSUD Undata Provinsi Sulawesi Tengah.

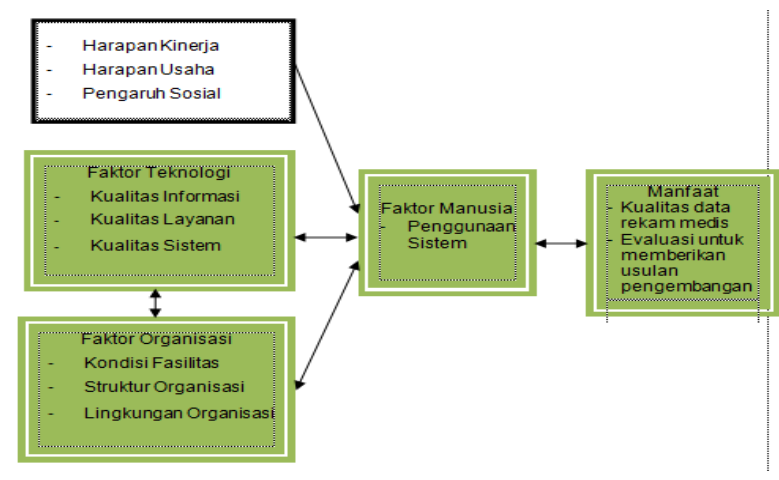

Gambar 3.1 Modifikasi Model Evaluasi UTAUT Model Evaluasi HOT $\mathrm{Fit}^{2,3}$ 
Subyek dalam penelitian ini adalah orang-orang yang berkaitan dengan SIRM dalam mengolah data rekam medis rawat inap di RSUD Undata Provinsi Sulawesi Tengah yaitu 1 orang Kepala Bidang Rekam Medik dan Informasi, 1 orang Kepala Seksi rekam medis, 1 orang bagian pemasukan data di ruang rawat inap, 2 orang petugas input bagian ruangan rekam medis, 3 orang petugas bagian output, 1 orang petugas penerimaaan pasien rawat inap (TPPRI) dan 1 orang pihak ketiga.

Pengumpulan data dilakukan sekaligus pada satu kali kegiatan pengamatan. Metode sampling yang digunakan adalah purposive sampling. Pengumpulan data dengan cara wawancara mendalam (indept interview), observasi dan telaah dokumen. Analisis data pada penelitian ini menggunakan metode content analysis yaitu mengumpulkan data, reduksi data, verifikasi dan kemudian disajikan dalam bentuk deskriptif, dengan mengikuti pola berpikir induktif yaitu pengujian data bertitik tolak dari data yang telah terkumpul, kemudian dilakukan penarikan kesimpulan.

\section{HASIL DAN PEMBAHASAN Karakteristik Informan}

Informan yang berjenis kelamin perempuan lebih banyak dari yang berjenis kelamin laki-laki, dilihat dari umur rata-rata 30 tahun ketas merupakan umur yang cukup matang dalam perkembangan jiwa seseorang. Berdasarkan karakteristik umur tersebut menunjukkan bahwa kecenderungan informan mempunyai produktivitas kerja yang tinggi dan cukup matang. ${ }^{4}$ Latar belakang pendidikan S1 sebanyak 2 orang, D3 sebanyak 2 orang, SMU sebanyak 3 orang dari ke 7 informan utama tersebut hanya dua orang yang berlatar belakang pendidikan rekam medis, yaitu IU.4 dan IU.6. Pada IU.1, IU.2 dan IU.3 bagian pendaftaran, input data di ruang rawat inap dan bagian rekam medis terdapat latar pendidikan yang tidak sesuai dengan kompetensi dengan pekerjaannya. Ditinjau dari pekerjaan masih terdapat 1 orang pegawai honorer dan 6 lainnya sudah PNS. Masa kerja yang paling lama 23 tahun dan yang paling sedikit adalah 3 tahun.

Dalam penelitian kualitatif membutuhkan keandalan seorang peneliti untuk menganalis, maka peneliti disebut sebagai instrumen kunci, karena peneliti adalah orang yang akan mengembangkan sistem. Selain itu dalam penelitian kualitatif untuk mengecek keabsahan data maka perlu menggunakan triangulasi. ${ }^{5}$ Menurut Nasution, triangulasi selain untuk mengecek kebenaran data juga dapat digunakan untuk memperkaya data dan menyelidiki validitas tafsiran peneliti terhadap data, karena itu triangulasi bersifat reflektif. ${ }^{6}$ Teknik triangulasi yang paling banyak digunakan ialah pemeriksaan melalui sumber lain.

\section{Evaluasi SIRM di RSUD Undata}

Berdasarkan hasil observasi terhadap implementasi SIRM bahwa sistem pengelolaan rekam medis rawat inap yang ada saat ini belum berjalan sesuai dengan tujuan awal di terapkannya sistem informasi ini, banyak permasalahan dan kendala yang terjadi dalam pengelolaan rekam medis rawat inap saat ini untuk menghasilkan informasi yang akurat, tepat waktu dan relevan. Masalah-masalah dalam pengelolaan rekam medis rawat inap antara lain:

1. Bagian TPPRI

Pada bagian TPRRI terjadinya kesulitan dalam membedakan kasus 
baru atau lama. Masalah ini disebabkan pasien yang pernah datang masuk berobat di rumah sakit pada umumnya tidak membawa kartu berobat, sehingga setiap pasien masuk dibuatkan kartu rawat inap baru menyebabkan duplikasi data tidak dapat dihindari dan penginputan data dilakukan berulang-ulang. Hal ini akan menghambat dalam pembuatan laporan morbiditas, karena sulit membedakan pasien lama \& baru, beban kerja petugas bertambah serta penumpukan data diruang penyimpanan.

2. Bagian ruang rawat inap.

Pembuatan laporan sensus harian rawat inap masih dilakukan secara manual pada format kosong yang telah disediakan oleh bagian rekam medis setelah itu di input di MS. excel sehingga laporan yang diperoleh tidak akurat, tepat dan terlambat.

3. Bagian rekam medis

Bagin ini mengalami kesulitan dalam pembuatan laporan internal dan eksternal untuk keperluan manajemen rumah sakit. Dimana proses pelaporan internal dan eksternal pengguna tidak menggunakan output dari SIRM, melainkan laporan yang dibuat mengunakan laporan manual pada kertas setelah itu di input di MS Excel sehingga penyajiannya tidak tepat waktu lebih dari 6 jam bahkan sampai 5 bulan berjalan belum ada laporan. Hal ini menyebabkan pengiriman laporan ke Dinas Kesehatan terlambat sehingga proses umpan balik dari Dinas Kesehatan ke Rumah Sakit untuk tindak lanjutnya terlambat.

\section{Faktor Manusia pada SIRM}

Manusia sebagai sumber daya manusia dalam menjalankan SIRM adalah mereka yang bertugas langsung berhubungan dengan sistem ini. Berdasarkan data karakteristik informan utama pada Tabel 1 terdapat sumber daya manusia bagian input pendaftaran dan ruangan rekam medis adalah berpendidikan SMA sederajat, dari latar belakang pendidikan tersebut tidak sesuai dengan pekerjaan yang dilakukan. Sebagai seorang operator harus memiliki latar belakang pendidikan yang sesuai seperti D3 rekam medis atau D3 komputer, serta memiliki keterampilan melalui pelatihan yang berkaitan dengan sistem informasi, pengolahan data, mampu mengoperasikan PC yang terhubung dengan jaringan. Sesuai dengan teori yang mengatakan bahwa untuk memperbaiki efektivitas karyawan dalam mencapai hasil kerja yang telah ditetapkan, serta memperbaiki penguasaan keterampilan dan teknik-teknik pekerjaan tertentu, terinci dan rutin maka perlu

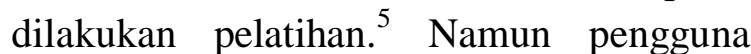
SIRM belum pernah mendapatkan pelatihan terkait sistem informasi hanya sebatas sosialisasi. Hal ini sesuai dengan ungkapan salah satu informan utama.

Kotak 3

...kalau untuk pelatihannya untuk secara umum dan lebih spesifik materinya tidak ada karena mereka vendornya langsung masuk keruanganruangan langsung didampingi saat aplikasi itu diterapkan sampai selesai sampai lancar kitanya mbak kalau belum lancar diajar lagi kalau tidak yah otodidak belajar sendiri atau tanya sama teman yang lebih paham mba....(IU 1,2,3,4,5,6,7)

Kalau mendengar dalam penggunaan SIRM ini, iya kita dengar ada pengarahan, ada dari teman yang ajar dan disampaikan juga kalau mau launcing sistem ini tapi kitakan basiknya bukan disini untuk software ini jadi yah belajar sendiri lagi......(IU 2,4,5,6,7)

... lalukan ada di ini pertemuan di aula juga jadi sy pernah ikut menyimak saja....(IU 3) 
Hal senada juga diungkapkan oleh informan triangulasi bahwa belum ada pelatihan untuk meningkatkan keterampilan dalam menjalankan sistem informasi rekam medis karena terbatasnya anggaran, dan belum dianggap prioritas. Hal ini dapat dilihat pada petikan wawancara pada kotak 4.

Kotak 4
...pelatihan khusus untuk sistem informasi belum
ada tergantung anggaran, kalau misalnya belum
ada anggaran mungkin untuk pelatihan, yah kita
belajar sama seniornya toh sama yang sudah ada
kita kasih training barangkali 1 atau 2 bulan
habis itu nah kalau mereka sudah bisa silahkan
kerja tapi kedepannya akan kami rencanakan di
tahun berikutnya pelatihan untuk meningkatkan
mutu kualitas SDM agar lebih baik lagi dan
kalau pelatihan berkaitan manajemen rekam
medis dan pelaporannya kami sudah ada....(IT
1,2)
...Eee kalau ini pelatihan tidak perlu, karena
orang-orang disistem ini sudah dilatih langsung,
apalagi pegawai baru sudah tahu komputer.....(IT
a.

Penerimaan sistem oleh pengguna untuk menggunakan SIRM berhubungan harapan kinerja, harapan usaha dan pengaruh rekan kerja. Karena seseorang yang meyakini bahwa pengguna yang terpengaruh oleh rekan kerja yang juga menggunakan dan menganggap sistem informasi penting dan bermanfaat, mampu meningkatkan kinerja, memudahkan dan mempercepat dalam pengolahan data serta meningkatkan kinerjanya. Hal ini sesuai dengan teori yang mengatakan bahwa perilaku pengguna sistem secara individu dipengaruhi oleh cara memandang perilaku dalam penggunaan teknologi. ${ }^{3}$

Pengguna SIRM di RSUD Undata yang ada saat ini sangat percaya bahwa sistem yang digunakan untuk mengolah data sangat penting dan bermanfaat.
Pengguna informan utama bahwa mereka merasa dengan menggunakan SIRM dapat meningkatkan kinerja, memperingan pekerjaan dan menghemat waktu karena tidak perlu input dua kali untuk pasien yang pernah berobat dan membawa kartu rekam medis, serta ada waktu untuk mengerjakan tugas yang lainnya. Hal ini sesuai dengan pendapat Jogianto, manajemen dengan menggunakan pendekatan sistem informasi merupakan langkah yang mengarah pada peningkatan efisiensi dan efektifitas kerja. ${ }^{7}$ Namun penerapan SIRM belum maksimal memberikan manfaat kepada pengguna karena output sistem belum sesuai kebutuhan pengguna. Berikut dapat dilihat petikan wawancara dengan informan utama tentang manfaat penggunaan SIRM pada kotak 5.

\section{Kotak 5}

...iya, kinerja saya meningkat dan waktunya lebih cepat dengan menggunakan sistem ini dalam input maupun penyajian data untuk pasien yang pernah berobat, yang belum pernah juga gampang inputnya sy masih bisa mengerjakan tugas yang lainnya ...(IU 1,2,3,4)

...belum maksimal mbak memang dengan adanya sistem ini pekerjaan kita jadi mudah, menghemat waktu dan tenaga sehingga pekerjaan cepat selesai dibandingkan manual dulu tapi untuk pelaporan kita harus membuat tabel laporan di excel lagi karena format yang di sistem tidak sesuai kebutuhan kita, diharapkan kedepannya jika ada pengembangan adanya tambahan menu misalnya menu filternya cuma perbulan kalau bisa per_tw dari tanggal berapa sampai tanggal berapa jadi kita bisa tahu kunjungan rawat inap peruangan, format laporan sesuai kebutuhan tanpa harus buat di excel lagi...(IU 5,6,7)

\section{Faktor Organisasi pada SIRM}

Dari hasil wawancara dan observasi, diperoleh bahwa kondisi fasilitas tersedia 
dan cukup memadai. Semua petugas mengunakan komputer perindividu untuk mendukung pengguna dalam menggunakan SIRM dan kondisi fasilitasnya dalam keadaan baik. Hal ini sesuai dengan teori bahwa kondisi-kondisi yang memfasilitasi pemakai mempunyai pengaruh kepada petugas, dengan semakin banyaknya fasilitas baik infrastruktur maupun sarana dan prasarana teknis lainnya yang disediakan organisasi untuk mendukung pemanfaatan sistem informasi maka kecenderungan seseorang untuk memanfaatkan sistem informasi semakin meningkat. ${ }^{6}$ Hal ini dapat dilihat pada petikan wawancara pada kotak 12

Kotak 12

...Semuanya dalam kondisi baik. Komputer, printer yang ada sudah cukup untuk mendukung segala kegiatan pengolahan data rekam medis, masing masing pegang komputer dan print jadi tidak perlu antri untuk ngeprint...(IT 1,2)

Dalam organisasi selain dukungan insfrastruktur yang dilihat, dukungan organisasi dalam hal kebijakan untuk mendukung sebuah sistem agar diketahui sejauh mana sistem sudah berjalan dan mencapai tujuan yang diharapkan. Kebijakan itu dilakukan dengan memonitoring SIRM yang diterapkan rumah sakit. Dari hasil penelitian informan utama menyatakan bahwa proses monitoring terhadap penerapan SIRM belum dilaksanakan sepenuhnya. Pihak manajemen baru sebatas melihat pelaksanaannya saja tanpa jadwal pengawasan yang teratur. Menurut Terry pada kegiatan monitoring, ada controlling yang merupakan salah satu fungsi manajemen. Dimana manajemen mengamati terus menerus pelaksanaan kegiatan sesuai rencana yang sudah disusun dan mengadakan perbaikan jika terjadi penyimpangan. ${ }^{8}$ Hasil penelitian di RSUD Undata informan triangulasi sudah melaksanakan monitoring namun belum terjadwal. Hal ini dapat dilihat pada petikan wawancara pada kotak 15

Kotak 16

...iya saya melakukan monitoring tapi tidak setiap hari, saya bisa mengontrol, ee apa yang menjustis laporan itu setiap saat selalu tersedia...(IT 1)

...monitoring sudah dilakukan saya lihat sistem kalau petugas bilang bermasalah saya koordinasikan dengan pihak ketiga misalnya masalah dikomputernya, data apa yang dimasukan lagi...(IT 2)

\section{Faktor Teknologi pada SIRM}

Menurut Yusof et al, faktor teknologi dapat dilihat dari kualitas sistem, kualitas informasi dan kualitas layanan. ${ }^{2}$ Dari hasil penelitian kualitas sistem yang dihasilkan dari SIRM pengguna sistem menyatakan bahwa sistem mudah digunakan, mudah diakses dengan menggunakan username dan password namun masih perlunya perbaikan dan penambahan form pada aplikasi, misalnya menghitung umur masih menggunakan bantuan kalkulator. Hal ini dapat dilihat pada Gambar 1. Selain itu kualitas informasi yang ada saat ini memang sudah cukup memudahkan dalam pekerjaan mereka. Namun bukan hanya mudah saja yang diperlukan dalam sistem tetapi harus tepat, akurat dan relevan. Informasi yang dihasilkan oleh SIRM masih terkendala waktu yang yang belum sesuai harapan, masih ditemui nomor rekam medis pasien ganda, dtd penyakit, data dokter dan ruangan masih sering kosong pada tabel. Output sistem belum sesuai kebutuhan yang seharusnya laporan morbiditas ada kolom Daftar Tabulasi Dasar 
(DTD). Dapat dilihat pada Gambar 2. Pembuatan laporan dibuat terpisah dari cara pembuatan yang masih manual. Hal ini dapat dilihat pada Gambar 3 dibawah ini

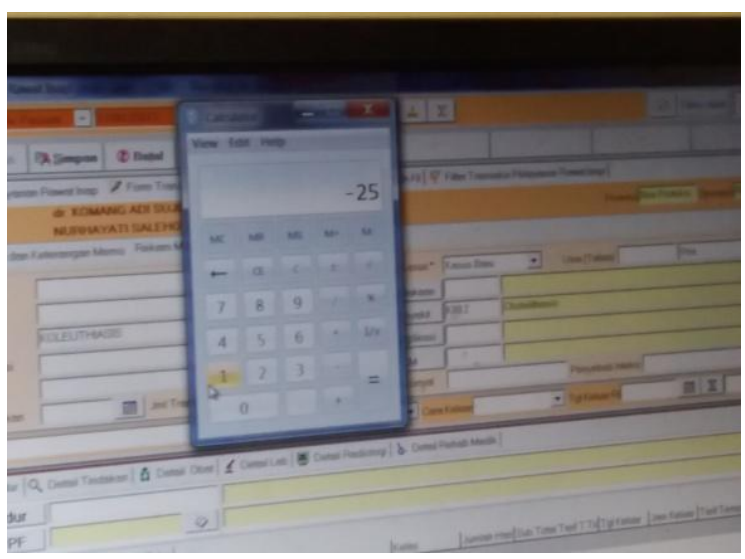

Gambar 1. Input umur

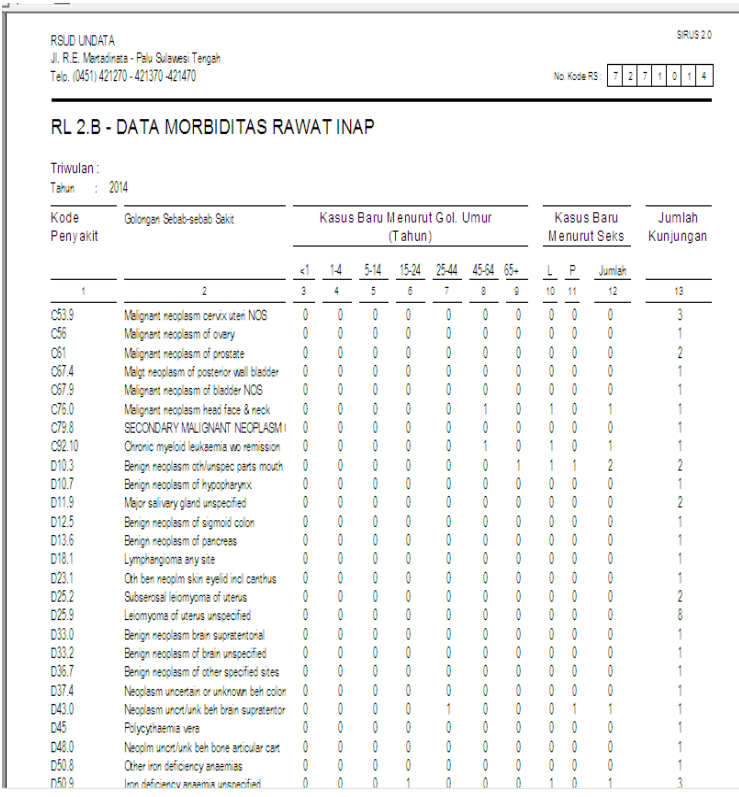

Gambar 2. Output SIRM

Untuk kualitas layanan Yusof et al, berpendapat bahwa kualitas layanan berfokus pada keseluruhan dukungan yang diterima oleh service provider sistem atau teknologi. $^{2}$ Service quality dapat dinilai dengan kecepatan respon, jaminan, empati dan tindak lanjut layanan. Hasil penelitian dengan informan utama dan triangulasi menyatakan bahwa layanan yang diberikan pihak ke-3 bila terjadi kerusakan yang tidak bisa ditangani pengguna pada perangkat lunak dalam hal ini SIRM, dikatakan kurang baik, kecepatan respon dari pihak ke-3 dalam menanggapi jika ada kendala lebih dari 24 jam. Untuk layanan internet pendukung penerapan SIRM belum juga mendapat layanan yang cukup baik, dilihat dari sering tidak stabilnya jaringan internet yang digunakan serta layanan provider jaringan sangat kurang karena harus menunggu hingga $>24$ jam.

Menurut Kotler yang berpendapat bahwa semakin tingginya tingkat kualitas pelayanan menyebabkan semakin tingginya tingkat kepuasan pelanggan. ${ }^{9}$ Namun yang terjadi di RSUD Undata kepuasan pengguna belum optimal karena pihak provider belum mampu memberikan pelayanan dengan cepat dan waktu respone yang lama kepada pengguna SIRM.

\section{KESIMPULAN}

Berdasarkan hasil penelitian yang telah dilakukan, maka dapat disimpulkan bahwa segi penggunaan sistem rutin digunakan setiap hari pada jam kerja, mudah penggunaannya, mudah dipelajari dan dipahami serta memudahkan petugas dalam menyelesaikan tugas, namun belum dapat maksimal meningkatkan kinerja pekerja karena form laporan belum sesuai kebutuhan. Dan rekan kerja dalam hal ini atasan belum pernah mengadakan pelatihan khusus mengenai sistem pengolahan data untuk menggunakan sistem informasi, belum adanya dukungan organisasi berupa supervisi langsung pada sistem informasi rekam medis. Sumber daya manusia dilihat dari latar belakang pendidikan, yaitu data entry operator tidak sesuai dengan job description. Selain itu informasi yang dihasilkan belum terpenuhi sesuai kebutuhan karena data hasil output dari 
sistem belum lengkap, akurat dan relevan. Data yang ada belum bisa digunakan dan dimanfaatkan langsung untuk perencanaan dan pengambilan keputusan. Pelayanan pihak provider kurang memuaskan pengguna. Dari hal tersebutlah yang menyebabkan belum terpenuhnya semua harapan pengguna dalam penerapan SIRM.

Rekomendasi untuk sistem informasi rekam medis di RSUD Undata Provinsi Sulawesi Tengah yaitu kedepannya disiapkan anggaran khusus untuk pelaksanaan sosialisasi dan pelatihan bagi anggota Tim dan pegawai di lingkungan RSUD Undata Provinsi Sulawesi tengah sebagai cara mengenalkan dan merangsang kepedulian pegawai terhadap SIRM sehingga dapat meminimalisir kasus duplikasi data, data tidak lengkap, melakukan monitoring yang terjadwal terhadap SIRM, agar penerapan SIRM dapat berjalan maksimal dan merekrut tenaga yang sesuai dengan kualifikasi yang dibutuhkan.

\section{Ucapan Terima kasih}

Kami mengucapkan terima kasih kepada Program Studi Magister Ilmu Kesehatan Masyarakat Universitas Diponegoro yang telah memberikan dukungan dan bimbingan selama proses pendidikan.

\section{DAFTAR PUSTAKA}

1. Depkes RI. Peraturan Menkes Nomor 269/Menkes/PER/III/2008 Tentang Rekam Medis. Jakarta: Kementerian Kesehatan Republik Indonesia, 2008.

2. Yusof MM, Kuljis J, Papazafeiropoulou A, et al. An evaluation framework for Health Information Systems: human, organization and technology-fit factors (HOT-fit). Int J Med Inform 2008; 77: 386-398.

3. Venkatesh, Morris, Davis, et al. User Acceptance of Information Technology: Toward a Unified View. MIS Q 2003; 27: 425.

4. Nursalam. Konsep Dan Teori Metodologi Penelitian Ilmu Keperawatan. 2008. Epub ahead of print 2008. DOI: 10.1007/0-38736274-6_24.

5. Gibson, Ivancevich D. Organisasi dan Manajemen $\square$ : Perilaku, Struktur dan Proses. 2010.

6. Nasution S. Metode Penelitian Kualitatif. Bandung: Tarsito, 2003.

7. Jogiyanto H.M. Analisis Dan Desain. Analisis Dan Desain 2005; 8.

8. Terry GR. Asas-asas Manajemen. Bandung: Alumni, 1986.

9. Kotler P. Manajemen Pemasaran. Jakarta: Erlangga, 2013. Epub ahead of print 2013. DOI: 10.1074/jbc.M303084200. 